\title{
Long-term changes in the diel vertical migration behaviour of zooplankton
}

\author{
G. C. Hays ${ }^{1, *}$, A. J. Warner ${ }^{2}$, D. Lefevre ${ }^{3}$ \\ ${ }^{1}$ School of Biological Sciences, University of Wales Swansea, Singleton Park, Swansea SA2 8PP, United Kingdom \\ ${ }^{2}$ The Sir Alister Hardy Foundation for Ocean Science, The Laboratory, Citadel Hill, Plymouth PL1 2PB, United Kingdom \\ ${ }^{3}$ School of Ocean Sciences, University of Wales Bangor, Menai Bridge, Gwynedd LL59 5EY, United Kingdom
}

\begin{abstract}
Samples historically collected and analysed by the Continuous Plankton Recorder survey were used to examine long-term (1958 to 1994) patterns in the normal diel vertical migration (NDVM) behaviour of 7 copepod taxa in the North Sea: Calanus finmarchicus C5-C6; Calanus spp. C1-C4; Centropages typicus; Centropages hamatus; Temora longicornis; Acartia clausii and Para-Pseudocalanus (this last group included all Paracalanus and Pseudocalanus species). The ratio of night: day abundance near the surface was used as a measure of the extent of NDVM. For all 7 taxa, the extent of NDVM between 1958 and 1994 co-varied with the abundance of herring Clupea harengus in the North Sea. Fisheries data show that during this period the herring stock was a good indicator of the overall abundance of planktivorous fish in the North Sea. These results suggest that changes in the abundance of planktivorous fish in the North Sea over recent decades have resulted in modifications in the NDVM

behaviour of many zooplankton taxa.
\end{abstract}

KEY WORDS: Zooplankton Diel vertical migration l Long-term patterns North Sea Predator evasion

\section{INTRODUCTION}

Diel vertical migration (DVM) is an almost ubiquitous feature of zooplankton communities and, consequently, has been the subject of extensive research over the last century (e.g. Hardy 1936). While the pattern of normal DVM (NDVM) is for populations to occur deeper during the day and shallower at night, reverse DVM (RDVM) (up during the day and down at night) also occurs. Strong evidence suggests that one of the principal functions of both NDVM and RDVM is to reduce the risk of mortality from predators: visually oriented predators in the case of NDVM and tactile predators in the case of RDVM (Lampert 1989). Evidence for this 'predator-evasion hypothesis' comes from a variety of sources. First, for example, NDVM tends to be most pronounced in larger and more heavily pigmented taxa (Hays et al. 1994), i.e. in those that are more readily perceived by visual predators and hence would have the highest risk of mortality if they

\footnotetext{
•E-mail:prime@sos.bangor.ac.uk
}

remained near the surface during the day. Second, for example, seasonal variations in NDVM occur so that migrating zooplankton only tend to be near the surface when illumination levels are low and hence when their risk of being perceived by visual predators is small (Russell 1934, Hardy \& Gunther 1936). Thus seasonal changes in the timing of NDVM occur in line with seasonal changes in day/night length with zooplankton shortening their daily period of near-surface foraging in the summer when nights are shorter and expanding their near-surface foraging in the winter when nights are longer (Hays et al. 1995).

Further evidence for the predator-evasion hypothesis has come from finding that long-term changes may occur in NDVM in line with changes in the intensity of visual predation. For example, Gliwicz (1986a) showed that the degree of NDVM in a series of lakes was correlated with each lake's history of occupation by planktivorous fish. More recently it has been shown that decadal (1960 to 1990) changes in the NDVM behaviour of the copepod Calanus finmarchicus have occurred in the North Sea in line with changes in the 
spawning stock biomass (SSB) of herring Clupea harengus in this region (Hays 1995a). Herring are planktivorous, with late copepodite stages of C. finmarchicus forming a major component of their diet (Last 1989). The implication of the covariation between the NDVM behaviour of $C$. finmarchicus and the herring abundance is, therefore, that in years when herring were abundant, the intensity of visual predation on C. finmarchicus was high and hence, as a consequence, this copepod showed relatively strong NDVM behaviour. Conversely in years when herring were scarce, the implication is that the intensity of visual predation on $C$. finmarchicus was relatively low and hence this copepod showed relatively weak NDVM behaviour (Hays 1995a).

Temporal changes in NDVM behaviour can occur as a result of direct behavioural responses by individual zooplankters to changes in fish abundance (Neill 1992). Alternatively, or additionally, increased fish abundance may lead to greater mortality of the nonmigrators within a zooplankton population and hence to changes in the observed extent of NDVM within the population as a whole (Pearre 1979, Gliwicz 1986b).

Here we provide a more detailed examination of long-term changes in the DVM behaviour of copepods in the North Sea. The previous work on the relationship between the NDVM behaviour of Calanus finmarchicus and the herring SSB assumes that the herring SSB provides a good measure of the overall intensity of visual predation on $C$. finmarchicus. To examine this assumption, we first consider whether the herring SSB reflects the total herring biomass in the North Sea and, second, we consider the relative abundance of herring compared to 3 other abundant planktivorous fish, Norway pout Trisopterus esmarkii, sandeel Ammodytes spp. and mackerel Scomber scombrus. If there have indeed been major changes in recent decades in the intensity of visual predation on C. finmarchicus in the North Sea, it might be predicted that changes in the NDVM behaviour of other copepods will also have occurred. We examine this prediction first by quantifying the strength of the NDVM behaviour aver recent decades for the other abundant copepods in the North Sea and second by comparing these long-term patterns with that observed for $C$. finmarchicus.

\section{MATERIALS AND METHODS}

Fisheries data. Information on the size of fish stocks in the North Sea was obtained from various ICES publications. Data on the herring SSB and the herring total biomass for the period 1958 to 1994 were obtained from Anonymous (1995) for the area south of $62^{\circ} \mathrm{N}$
Data on the total biomass of Norway pout and sandeel in the area south of $62^{\circ} \mathrm{N}$ for the period 1978 to 1989 were obtained from Anonymous $(1990 \mathrm{a}, 1994)$ using the most recent estimate available for the stock size in each year. Thus stock size for the period 1982 to 1989 was obtained from Anonymous (1994) and for the period 1978 to 1981 from Anonymous (1990a). Data on the total biomass of mackerel for the period 1978 to 1989 were obtained from Anonymous (1990b). The mackerel found in the North Sea largely belong to the Western Stock which migrates into the northern North Sea (approximately 57 to $63^{\circ} \mathrm{N}$ ) in the autumn from spawning grounds to the southwest of the UK. Based on figures given in Anonymous (1990b; Table 7.3) we assumed that, when averaged throughout the year, the biomass of mackerel in the North Sea represented $30 \%$ of the total Western Stock.

Zooplankton data. Zooplankton data came from the Continuous Plankton Recorder (CPR) survey. More complete details of this survey can be found in Warner \& Hays (1994). In short, CPRs have been towed regularly from ships of opportunity throughout the North Atlantic and North Sed from 1948 to the present, with the survey now being run by the Sir Alister Hardy Foundation for Ocean Science (SAHFOS). CPRs are towed near the surface (mean depth approximately $7 \mathrm{~m}$, Hays \& Warner 1993) and sample zooplankton on a $270 \mu \mathrm{m}$ mesh, with the samples being preserved in formalin inside the recorder. On return of the recorders to the laboratory, individual samples, each representing 10 nautical miles (approximately $18.5 \mathrm{~km}$ ) of tow, are analysed using standard procedures and the resulting data are entered into an electronic relational data-base.

In the standard analysis of CPR samples, the level of identification for different taxa varies. In the northern North Sea, the 7 most abundant calanoid copepod taxa in the CPR records are (copepodite stages C5-C6 unless otherwise stated): Calanus finmarchicus, Calanus spp. C1-C4, Centropages typicus, Centropages hamatus, Temora longicornis, Acartia clausii and Para-Pseudocalanus (this category includes all Paracalanus and Pseudocalanus species which are pooled to simplify the analysis procedure) (Oceanographic Laboratory Edinburgh 1973), with all these taxa having been identified since 1958. Due to their high abundance we focused our analysis on these 7 taxa. The prosome length of each taxon was taken from Hays et al. (1994) and references therein.

For species in which the amplitude of NDVM is relatively strong, the abundance near the surface will be higher during the night than it is during the day and hence the ratio of night:day abundance in the CPR records will be $>1.0$. Conversely when NDVM is relatively weak, abundance near the surface will be more 
similar between night and day and hence the ratio of night:day abundance will be less and will become 1.0 when there is no NDVM. Hence, as has been done before (Hays 1995a), the ratio of night: day abundance in the CPR records was used to provide a measure of the extent of NDVM in each year. This ratio, termed the $N / D_{\text {index }}$ was calculated by pooling all the CPR samples collected in each year in the study area and then using the equation:

$N / D_{\text {index }}=$

antilog $\left[\right.$ mean $\log \left(x_{\text {night }}+1\right)-$ mean $\left.\log \left(x_{\text {drly }}+1\right)\right]$

where $x_{\text {night }}$ and $x_{\text {day }}$ were the number of specimens per sample for samples collected between midnight $\pm 6 \mathrm{~h}$ and midday \pm 6 h respectively. The $\mathrm{SE}$ of the $N / D_{\text {index }}$ is given by:

$$
\mathrm{SE}=\sqrt{\left(\sigma_{\text {night }}^{2}+\sigma_{\text {day }}^{2}\right)\left(1 / n_{\text {night }}+1 / n_{\text {day }}\right)}
$$

where $\sigma^{2}$ nght and $\sigma^{2}$ day are the variances of the mean $\log \left(x_{\text {night }}+1\right)$ and the mean $\log \left(x_{\text {day }}+1\right)$ values respectively and $n_{\text {night }}$ and $n_{\text {day }}$ are the number of samples collected during midnight $\pm 6 \mathrm{~h}$ and midday $\pm 6 \mathrm{~h}$ respectively. As has been done before (Hays 1995a), we report zooplankton data for the area of the North Sea bounded by 54 to $60^{\circ} \mathrm{N}$ and $3^{\circ} \mathrm{W}$ to $10^{\circ} \mathrm{E}$ (Fig 1).
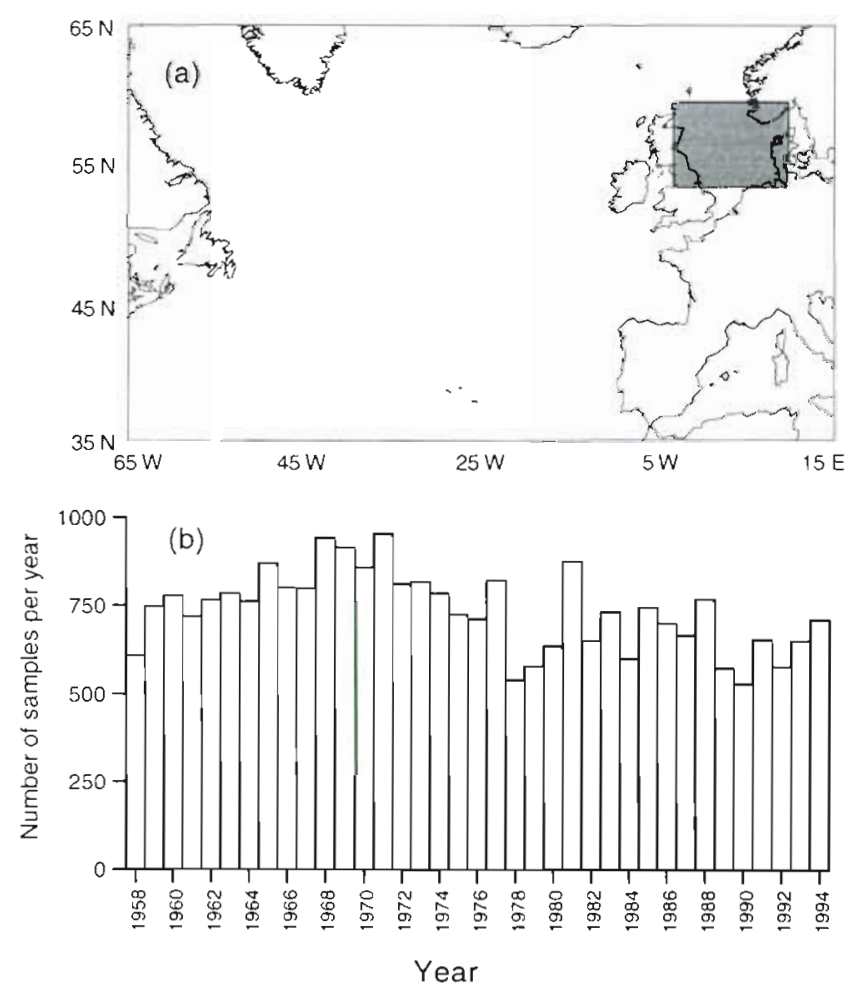

Fig. 1. (a) Study area (shaded) in the North Sea. (b) Number of analysed CPR samples collected in each year from the study area

\section{RESULTS}

\section{Fisheries data}

The SSB and total biomass of herring in the North Sea showed similar patterns between 1958 and 1994 , with higher values in the late 1950 s and early 1960s, declining to lower values in the 1970 s and then returning to higher values in the 1980 s (Fig. 2). These 2 indices of the herring abundance were extremely well correlated ( $r=0.92$ ) (Fig. $2 c$ ).

Data for the sum of the herring total biomass + the sandeel total biomass + the Norway pout total biomass + the mackerel total biomass (we termed this sum the 'combined planktivorous fish total biomass') in the North Sea were available for 1978 to 1989 (Fig. 3a).
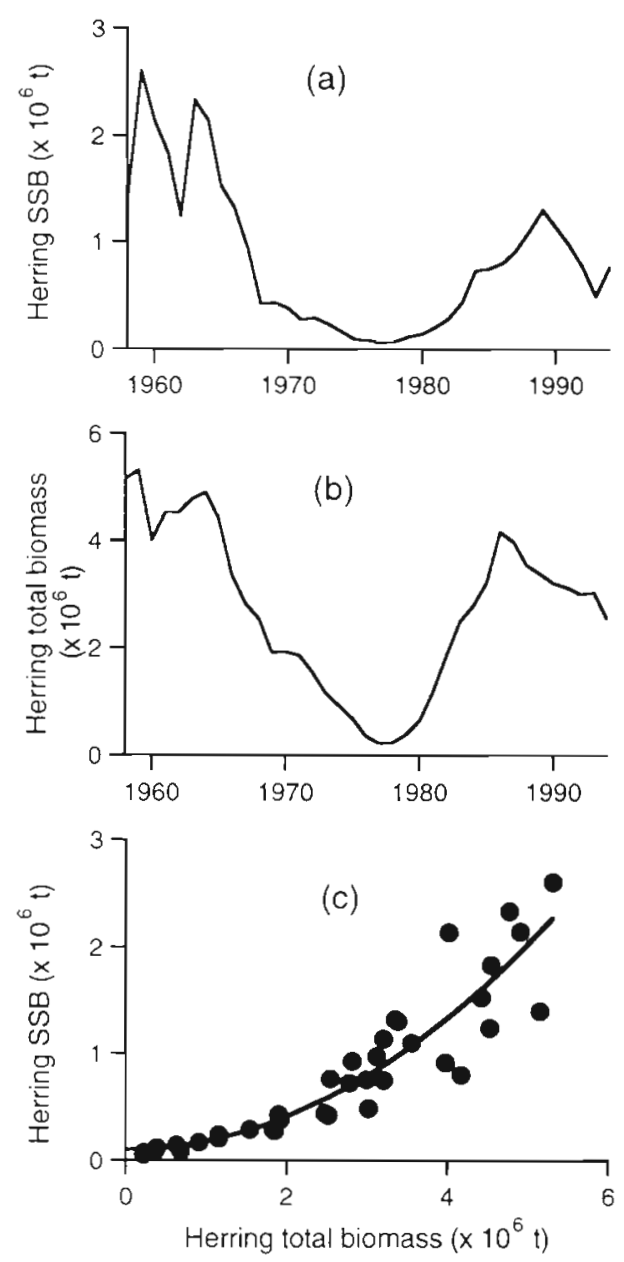

Fig. 2. Clupea harengus. (a) SSB of herring in the North Sea between 1958 and 1994. (b) Herring total biomass (i.e. mature + immature fish) in the North Sea between 1958 and 1994. (c) SSB of herring plotted against the total biomass of herring $(h)$ for 1958 to 1994. SSB $=0.77 h^{3}+0.101\left(F_{1.35}=177, r^{2}=0.84\right.$, $\mathrm{p}<0.001)$ 
During this period the combined planktivorous fish total biomass showed a progressive increase from approximately $4 \times 10^{6} \mathrm{t}$ in 1978 to approximately $8 \times$ $10^{6} \mathrm{t}$ in the mid 1980s. The total biomass of herring accounted for a variable proportion of the combined planktivorous fish total biomass (Fig. 3b). For example, when herring were scarce in the 1970 s they accounted for approximately $6 \%$ of the combined planktivorous fish total biomass, but this percentage rose progressively through the 1980 s as the herring stock recovered. Thus in the late 1980s, herring accounted for approximately $55 \%$ of the combined planktivorous fish total biomass. There was a close correlation between the total biomass of herring and the combined planktivorous fish total biomass (Fig. 3c).
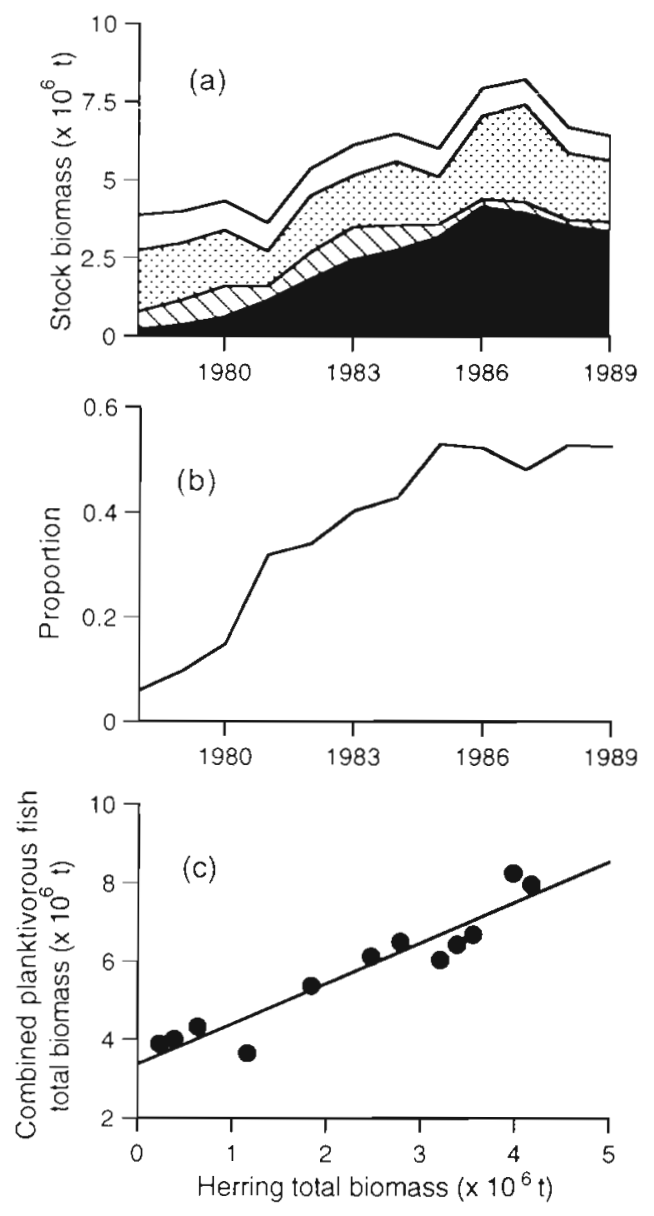

Fig. 3. Clupea harengus, Trisopterus esmarkil, Ammodytes spp., Scomber scombrus. (a) Total bromass of herring (a),

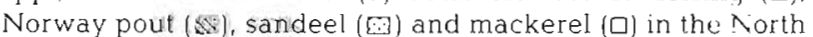
Sea between 1978 and 1989. (b) Herring total biomass between 1978 and 1989 expressed as a proportion of the combined planktivorous fish total biomass. (c) Relationship between the combined planktivorous fish total biomass and the herring total biomass for the period 1978 to 1989 . Combined planktivorous fish total biomass $=1.03$ (Herring total biomass $)+3.38\left(F_{1.10}=92.6, r^{2}=0.90, p<0.001\right)$

\section{Zooplankton data}

CPR sampling

In the study area of the North Sea, a total of 27089 CPR samples were collected between 1958 and 1994 and analysed. The sampling intensity was fairly uniform over this time period, with approximately 600 to 800 samples being analysed for each year (Fig. 1 b).

\section{DVM behaviour of C5-C6 Calanus finmarchicus}

The N/Dindex for C5-C6 Calanus finmarchicus was generally higher in the late 1950 s and early 1960 s, then lower in the 1970 s before it increased again in the 1980 s.
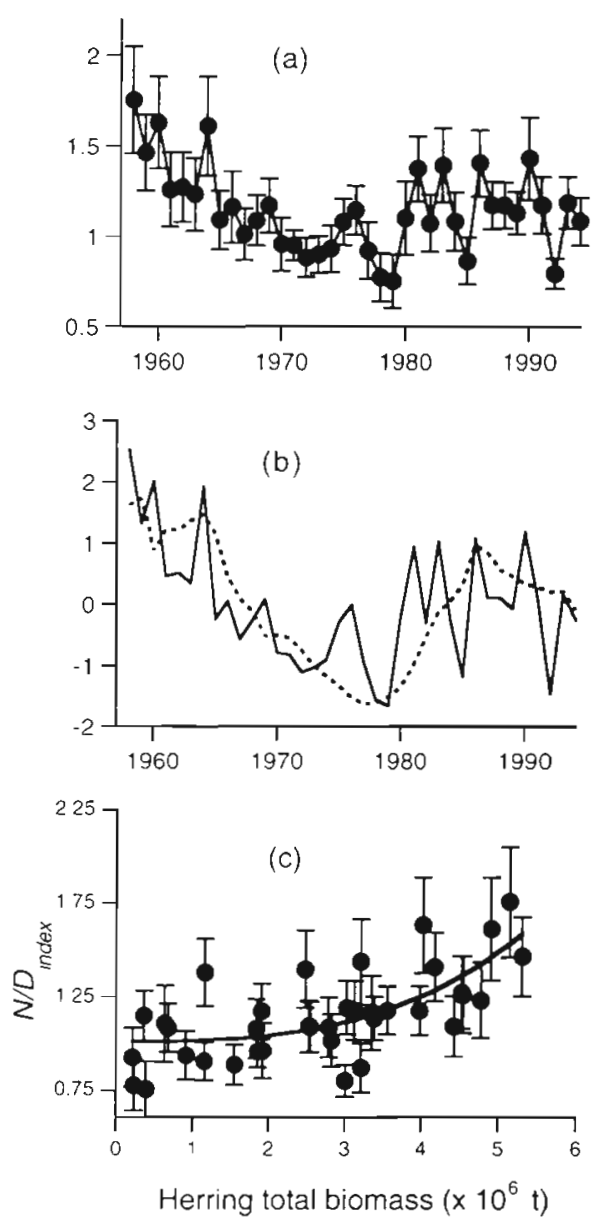

Fig. 4. Calanus finmarchicus, Clupea harengus. (a) N/D index for C5-C6 C. finmarchicus between 1958 and 1994. Error bars are $\pm 1 \mathrm{SE}$. (b) $N / D_{\text {index }}$ for C5-C6 C. finmarchicus (-) and the herring total biomass (---) , both reduced to zero mean and unit variance to facilitate visual comparison. (c) $N / D_{\text {indes }}$ for C5-C6 C. finmarchicus plotted against the herring total biomass $(h)$ for the period 1958 to $1994 . N / D_{\text {index }}=1.01+$ $0.00381 h^{3}\left(F_{1.35}=29.8, \mathrm{r}^{2}=0.46, \mathrm{p}<0.001\right)$ 
The annual values for the $N / D_{\text {index }}$ were positively correlated with the herring total biomass in the North Sea (Fig. 4). A cubic equation explained slightly more of the total variation in the $N / D_{\text {index }}$ than a linear fit although the difference was small ( $46.0 \%$ versus $41.9 \%$ ).

The unexplained variation in the relationship between the $N / D_{\text {index }}$ for C5-C6 Calanus finmarchicus and the herring stock may have been, at least partly, caused by the inaccuracy with which the $N / D_{\text {index }}$ was estimated in each year. To investigate this possibility we performed the following simulation. For the herring total biomass in each of the years (1958 to 1994, i.e. $n=$ 37 years) the $N / D_{\text {index }}$ for C5-C6 Calanus finmarchicus was predicted using the equation: $N / D_{\text {index }}=1.01+$ $0.00381 h^{3}$ where $h$ is the herring total biomass in millions of tonnes (Fig. 4). We termed this result the 'Pre- dicted $N / D_{\text {Index }}$. From the known accuracy with which the $N / D_{\text {index }}$ was estimated in each of the 37 years (Eq. 2) an error was then randomly selected (and hence could be either + or $\cdots$ ) and added to each Predicted $N / D_{\text {Index }}$ value. We termed the result the 'Modelled $N / D_{\text {Index }}$, i.e. Modelled $N / D_{\text {index }}=$ Predicted $N / D_{\text {index }}+$ error. The resulting correlation coefficient for the 37 years was then determined between the Modelled $N / D_{\text {index }}$ values and the herring total biomass ( $r_{\text {modelled }}$ ). We repeated this procedure 200 times and hence determined the frequency distribution for $r_{\text {modelled. }}$ The procedure is summarised graphically in Fig. 5. When the error with which the $N / D_{\text {index }}$ is estimated is very low, then $I_{\text {modelled }}$ will tend to be very near 1.0 . Conversely, when this error is greater, then $r_{\text {modelled }}$ will tend to be less (Fig. 5).
Fig. 5. Schematic representation of how the frequency distribution of $r_{\text {modelled }}$ was generated. Step 1 . $N / D_{\text {index }}$ for C5-C6 Calanus finmarchicus was predicted using $N / D_{\text {index }}=1.01+0.00381 h^{3}$ where $h=$ the herring total biomass $\left(\times 10^{6} \mathrm{t}\right)$. Step 2: An error was then randomly selected using the known accuracy with which the $N / D_{\text {index }}$ was estimated in each of the 37 years and added to each Predicted $N / D_{\text {index }}$ value to give the Modelled $N / D_{\text {index }}$, i.e. Modelled $N / D_{\text {index }}=$ Predicted $N / D_{\text {mdex }}+$ error; then $r_{\text {modelled }}$ for the 37 years was determined between the Modelled $N / D_{\text {index }}$ values and the herring total biomass. Step 3: Steps 1 and 2 were repeated 200 times and the resulting frequency distribution for $r_{\text {modeled }}$ was determined. If the error with which the $N / D_{\text {index }}$ is estimated is low then $r_{\text {modelled }}$ will tend to be very close to 1.0 but as this error gets larger then $r_{\text {modelled }}$ will tend to become less

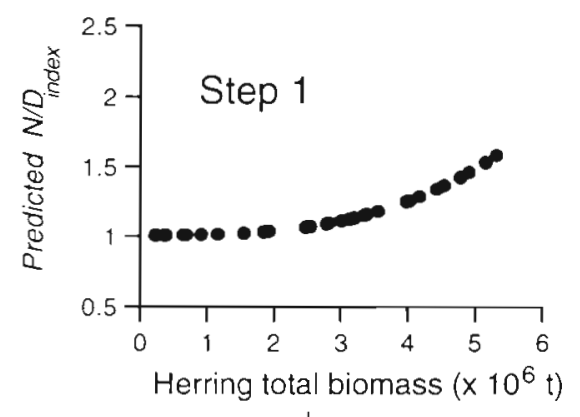

Step 2

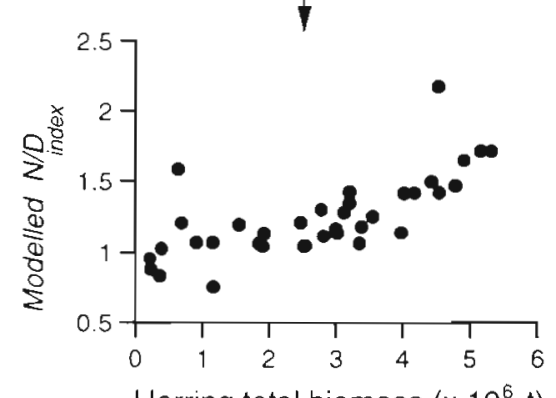

Herring total biomass $\left(x 10^{6} \mathrm{t}\right)$

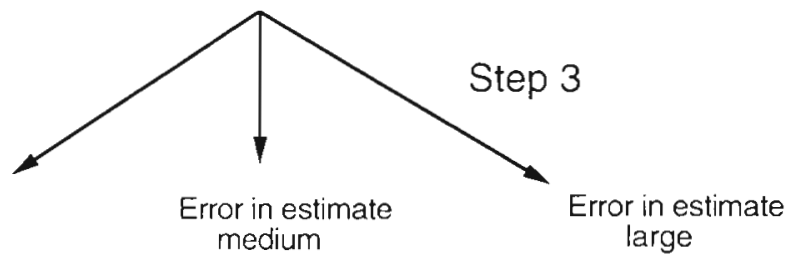

Error in estimate small

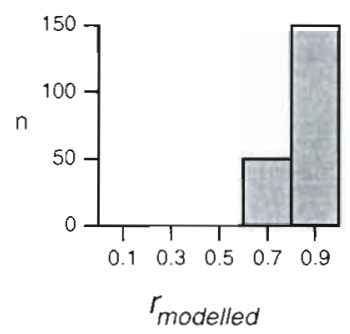

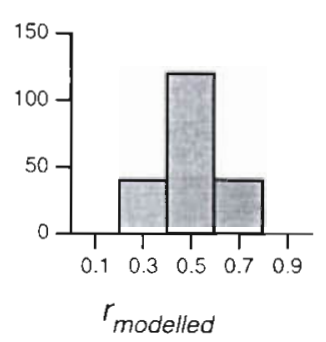

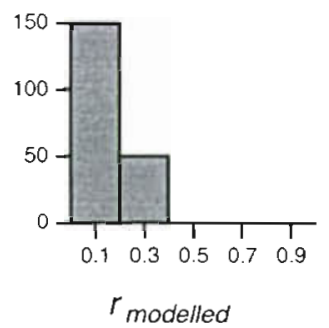


The frequency distribution of $r_{\text {modelied }}$ for the relationship between C5-C6 Calanus finmarchicus and the herring total biomass is shown in Fig. 6. The mean $r_{\text {modelled }}$ was 0.708 (SD $=0.096$, $\mathrm{n}=200$ trials). In other words, if the inter-annual variation in the $N / D_{\text {index }}$ of $\mathrm{C} 5-\mathrm{C} 6 \mathrm{C}$. finmarchicus was entirely due to inter-annual variations in the herring stock, then, due to the inaccuracy with which the $N / D_{\text {index }}$ was estimated in each year, the correlation coefficient we would expect to observe between the $N / D_{\text {index }}$ for C5-C6 C. finmarchicus and the herring stock would be only about 0.708 . The observed correlation coefficient for this relationship (0.678; see Fig. 4 ) is very close to, and not significantly different from, this mean value for $r_{\text {modelled }}$ $(Z=-0.31, p=0.76)$. The implication, therefore, is that other factors, aside from inaccuracy in the $N / D_{\text {index }}$ estimates, do not need to be invoked to account for the unexplained variation in the observed relationship between the $N / D_{\text {index }}$ of C5-C6 C. finmarchicus and the herring total biomass.

\section{DVM behaviour of other calanoid copepods}

The $N / D_{\text {ndex }}$ was calculated for each of the years 1958 to 1994 for the taxa Calanus spp. C1-C4, Centropages typicus, Centropages hamatus, Temora longicornis, Acartia clausii and Para-Pseudocalanus. The $N / D_{\text {index }}$ time-series for each of these 6 taxa was then compared with the herring total biomass. In all 6 cases there was a significant relationship between the $N / D_{\text {index }}$ and the herring total biomass $(p<0.05)$

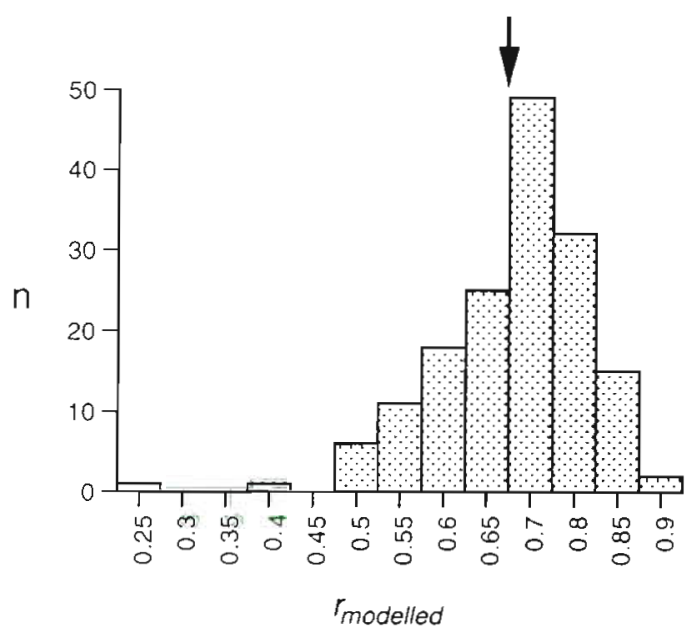

Fig. 6. Calanus finmarchicus, Clupea harengus. For $\mathrm{n}=200$ trials the frequency distribution of $r_{\text {modelled }}$ for the relationship between the Modelled $N / D_{\text {index }}$ for C5-C6 C. finmarchicus and herring total biomass. The value for the observed correlation $(0.678)$ is shown by the vertical arrow
Table 1 A summary of the observed correlation coefficients between the $N / D_{\text {index }}$ for each copepod taxon and the herring total biomass and the mean $r_{\text {miodelled }}$ values for each relationship

\begin{tabular}{|lrrr|}
\hline & Observed $r$ & Mean $r_{\text {riadelled }}$ & $\mathrm{SD}$ \\
\hline Calanus finmarchicus C5-C6 & 0.678 & 0.708 & 0.096 \\
Temora longicornis & -0.550 & -0.496 & 0.112 \\
Calanus spp. C1-C4 & 0.385 & 0.390 & 0.161 \\
Para-Pseudocalanus & -0.465 & -0.480 & 0.132 \\
Centropages typicus & 0.421 & 0.454 & 0.149 \\
Centropages hamatus & -0.422 & -0.410 & 0.155 \\
Acartia clausii & -0.388 & -0.484 & 0.111 \\
\hline
\end{tabular}

(Fig 7). However, the sign of the correlation coefficient varied between the 6 taxa. The $N / D_{\text {index }}$ for Calanus spp. $\mathrm{C} 1-\mathrm{C} 4$ and $\mathrm{C}$. typicus was positively correlated with the herring total biomass (Fig. 7b, d), whereas the $N / D_{\text {index }}$ for $T$ longicornis, Para-Pseudocalanus, $C$. hamatus and $A$. clausii were all negatively correlated with the herring total biomass (Fig. 7a, c, e, f).

To investigate whether the low correlation coefficients between the $N / D_{\text {index }}$ for these 6 taxa and the herring total biomass were a consequence of the inaccuracy with which the $N / D_{\text {index }}$ was estimated, we repeated the procedure outlined previously (Fig. 5), i.e. for each taxon the $N / D_{\text {index }}$ was predicted for each year from the herring total biomass (using the equations in the legend of Fig. 7) and then, using the known errors with which the $N / D_{\text {index }}$ was estimated (error bars in Fig. 7), an error was randomly selected to produce a Modelled $N / D_{\text {ndex }}$ value. The correlation coeffi-

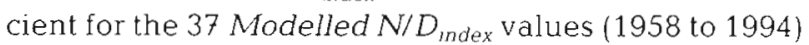
and the herring total biomass was then calculated $\left(r_{\bmod }\right.$. elled) and this simulation repeated 200 times. The frequency distributions for $r_{\text {modelled }}$ for these 6 taxa are shown in. Fig. 8. For each taxon the observed correlation coefficient was close to, and not significantly different from, the mean value for $r_{\text {modellod }}(|Z| \leq 0.87, \mathrm{p} \geq$ 0.38). As for C5-C6 Calanus finmarchicus, therefore, the inaccuracy with which the $N / D_{\text {index }}$ was estimated could account for the unexplained variation in the observed relationships between the $N / D_{\text {index }}$ values for these 6 taxa and the herring total biomass (Table 1).

The correlation coefficients for the relationships between the $N / D_{\text {Index }}$ values for each taxon and the herring total biomass (Table 1) were plotted against the size of each copepod taxon (Fig. 9). A logistic equation was fitted to the observations with the form:

$$
r+1=\frac{r_{\infty}+1}{1+\exp \left[k_{1}\left(r+k_{2}\right)\right]}
$$

where $r$ is the correlation coefficient, $r_{\infty}$ is the upper asymptote and $k_{1}$ and $k_{2}$ are constants. From the observed inaccuracy with which the $N / D_{\text {ndex }}$ was 
Fig. 7 Relationships for the years 1958 to 1994 between the $N / D_{\text {index }}$ for 6 taxa of calanoid copepods and the herring total biomass $(h)$. (a) Temora longicornis: $N / D_{\text {index }}=1.10-0.0011 h^{3}\left(F_{1.35}=15.2\right.$ $\left.r^{2}=0.30, p<0.001\right)$. (b) Calanus spp. C1-C4: N/D index $=1.02+0.00093 \mathrm{~h}^{3}$ $\left(F_{1,35}=6.1, r^{2}=0.15, p=0.019\right)$. (c) Para-Pseudocalanus: $N / D_{\text {index }}=1.18-$ $0.00159 h^{3}\left(F_{1,35}=9.7, \mathrm{r}^{2}=0.22, \mathrm{p}<0.01\right)$ (d) Centropages typicus: $N / D_{\text {adax }}=$ $0.971+0.00058 h^{3}\left(F_{1.35}=7.5, \mathrm{r}^{2}=0.18\right.$ $\mathrm{p}=0.01)$. (e) Centropages hamatus $N / D_{\text {index }}=1.02-0.00030 h^{3}\left(F_{1.35}=7.6\right.$ $\mathrm{r}^{2}=0.18, \mathrm{p}<0.01$ ). (f) Acartia clausii $N / D_{\text {index }}=1.20-0.0015 h^{3}\left(F_{1,35}=6.2\right.$ $\left.r^{2}=0.15, p=0.018\right)$
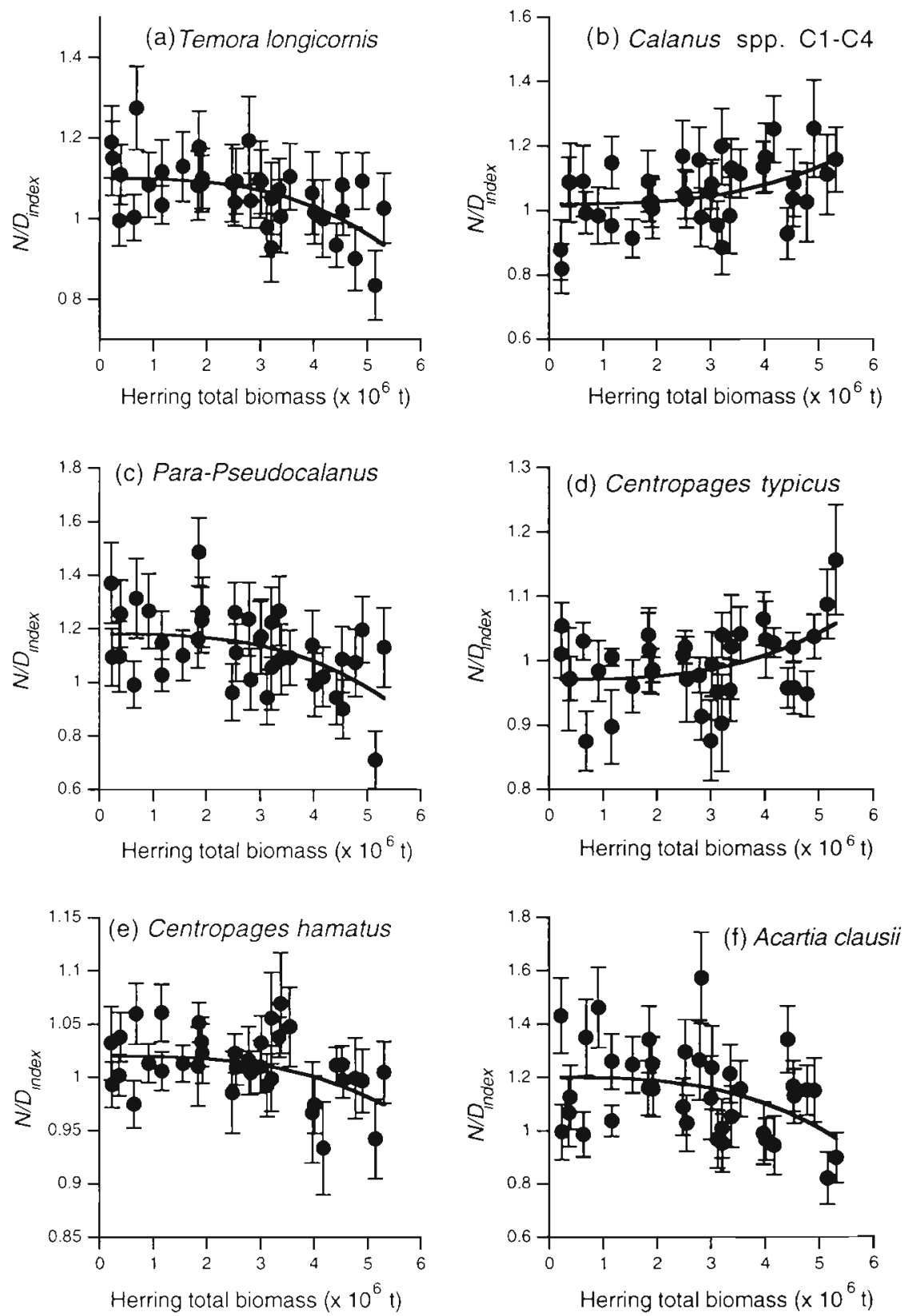

quantified (Table. 1), we assumed that $r_{\infty}$ was 0.708 . We calculated $k_{1}$ and $k_{2}$ in order to give the best fit to the observations using the Solver routine of Microsoft Excel 5.0. The fitted logistic model gave $k_{1}=-3.37$ and $k_{2}=-1.5$ and explained $84 \%$ of the observed variation in the values of $I$ (Fig. 9) $\left(F_{1,5}=25.8, r^{2}=0.84, p<0.01\right)$.

\section{DISCUSSION}

Predators may have a variety of strong impacts on the structure and functioning of pelagic ecosystems
(Verity \& Smetacek 1996). The consequence of this 'top-down' control is that changes in the intensity of predation may cause concomitant changes within individuals, populations and communities at lower trophic levels. Brooks \& Dodson (1965), for example, showed that the introduction of planktivorous fish to freshwater lakes caused a reduction in the size of the zooplankton as a result of predation on the larger forms. Similarly, changes may occur in the life-history strategies of individual species. For example, in the presence of planktivorous fish, the cladoceran Daphnia matures earlier and lays larger clutches of eggs (Machacek 

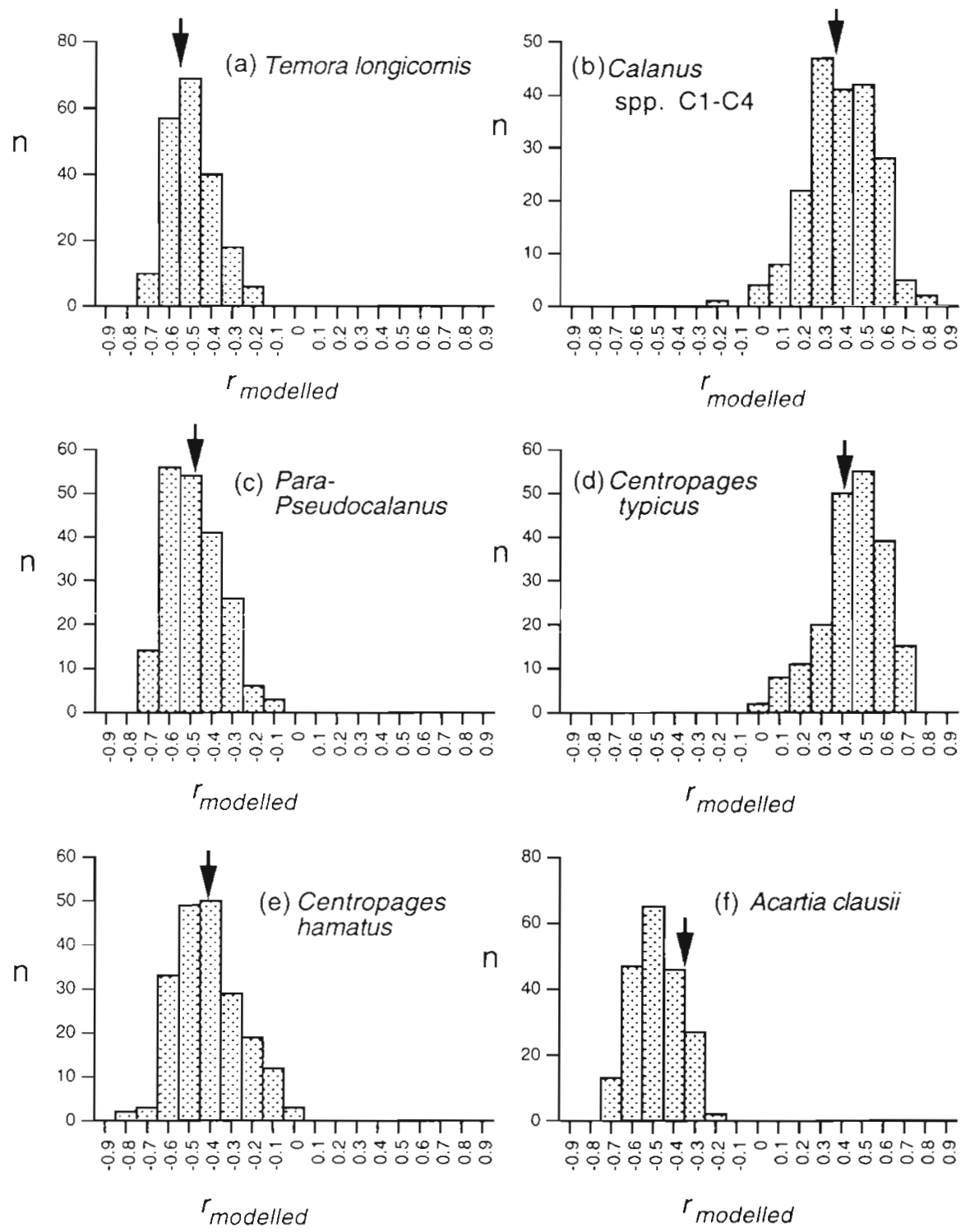

Fig. 8. The $r_{\text {modelled }}$ frequency distributions for (a) Temora longicornis, (b) Calanus spp. C1-C4, (c) Para-Pseudocalanus, (d) Centropages typicus, (e) Centropages hamatus, and (f) Acartia clausii. $\mathrm{n}=200$ trials in each case. The observed correlation coefficients are shown by the vertical arrow on each graph
1993). It has been widely argued that zooplankton exhibit DVM principally in order to reduce their risk of mortality from predators (Lampert 1989). When the dominant predators occur near the surface and use vision to locate their prey (such as many planktivorous fish), then NDVM tends to occur with the zooplankton occurring deeper during the day and coming to the surface only at night when their probability of being perceived and hence consumed by the visual predators is greatly reduced. Conversely, if tactile predators dominate and are themselves exhibiting NDVM, then their zooplankton prey show RDVM and in this way the zooplankton prey increase their spatial separation from their predators (Ohman et al. 1983, Neill 1990). In experimental enclosures changes in the DVM behaviour of zooplankton have been shown to occur in response to changes in the intensity of predation (Neill 1992). That these experimentally induced changes in DVM behaviour may occur within only a few hours suggests that the DVM changes may occur as a result of behavioural plasticity of individuals and not simply by selective predation (Pearre 1979, Gliwicz 1986b).

Given this influence of predators on the DVM behaviour of zooplankton, it would be predicted that changes in the intensity of predation in natural environments, if of sufficient magnitude, should induce changes in zooplankton behaviour. The observations of Bollens \& Frost (1989) that temporal variability in the NDVM behaviour of the marine copepod Calanus pacificus was correlated with the abundance of their fish predators provided evidence that predator induced natural 


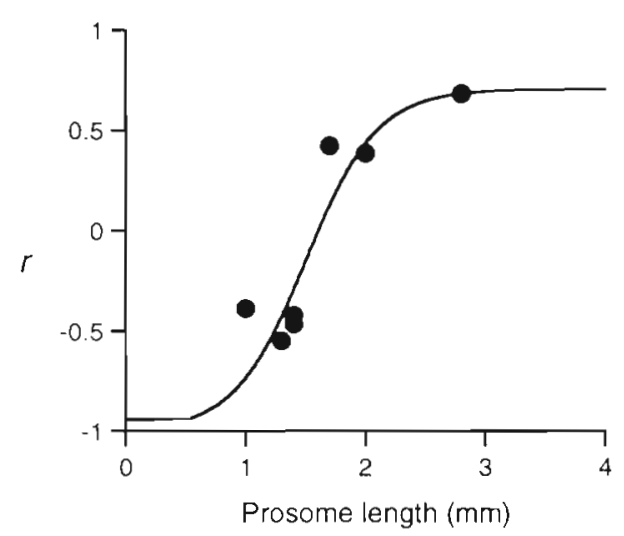

Fig. 9. The observed correlation coefficient ( $r$ ) between the $N / D_{\text {Index }}$ for each copepod taxon and the herring total biomass (values given in Table 1) plotted against the prosome length of each copepod taxon. The fitted logistic model (see text for details) explains $84 \%$ of the variation in $r$

changes in DVM behaviour may indeed occur in marine environments. More recently we have shown that in the North Sea, changes in the DVM behaviour of C5-C6 Calanus finmarchicus between 1960 and 1990 were well correlated with the SSB of herring, again suggesting that the changes in DVM behaviour were predator induced (Hays 1995a). However, our previous study might be criticised (1) because the SSB of herring may not be a good measure of the overall biomass of the herring population, and (2) because herring are only 1 of several fish that feed on C5-C6 C. finmarchicus and hence changes in the stock of herring may not reflect changes in the total planktivorous fish biomass.

Fisheries data for the North Sea are collected by various countries, such as Scotland, Norway and Denmark, with these data then being used by ICES working groups to produce annual assessments of stock size. The ICES working group reports contain the most comprehensive and definitive estimates for the stock size of the various species in the North Sea (see, for example, previous use of this data by Corten 1990 , Corten \& van de Kamp 1992, Harris \& Bailey 1992, Monaghan 1992) and were therefore used here. Due to its socio-economic importance, the herring fishery in the North Sea has been the subject of continued research and assessment over the last century (Burd 1978, Cushing 1980). The collapse of this stock in the 1970 s has been well documented and led to the eventual closure of the fishery for a period in the late 1970 s (Corten 1990, Corten \& van de Kamp 1992). The ICES working group data showed that in the North Sea the herring total biomass and spawning stock biomass displayed broadly similar trends between 1958 and 1994, with high abundance in the late 1950 s and early 1960 s declining to low abundance in the 1970 s and then rising to higher abundance again in the 1980s. The SSB which we have used previously as an index of herring abundance (Hays 1995a) clearly provides a good measure of the total herring biomass in this region.

Aside from herring, 3 other planktivorous fish that occur abundantly in the North Sea are sandeel, Norway pout and mackerel (Monaghan 1992). Data on the total biomass of all 3 of these species in the North Sea were available from 1978. Before this time, data for sandeel and Norway pout in the ICES working group reports are given in units of numbers rather than biomass and so are not directly comparable with the 1978 to 1989 data. As might be expected, when herring were scarce in the 1970 s they accounted for only a small proportion of the combined herring + sandeel + Norway pout + mackerel total biomass, but as the herring stock recovered in the 1980 s they accounted for an increasing proportion of the combined total biomass. The herring total biomass accurately reflected the combined herring + sandeel + Norway pout + mackerel total biomass within the period 1978 to 1989 . We therefore conclude that the long-term changes in the herring stock that occurred between 1958 and 1994 probably give a good indication of the overall intensity of visual predation on large copepods such as C5-C6 Calanus finmarchicus.

The major benefit of using the CPR survey to examine NDVM is that there is a huge (both spatially and temporally) data-base of analysed samples (Fig, 1b) which allows aspects of the DVM behaviour of zooplankton to be accurately quantified (e.g. Hays et al. $1994,1995)$. The very high towing speed of CPRs (typically 12 to $20 \mathrm{knots}$ or 600 to $1000 \mathrm{~cm} \mathrm{~s}^{-1}$ ) means that differential day:night avoidance of the CPR by copepods is likely to be negligible (Hays 1995b) and hence the ratio of night to day abundance in the CPR records may reveal the extent of DVM. The $N / D_{\text {index }}$ for C5-C6 Calanus finmarchicus between 1958 and 1994 was positively correlated with the herring total biomass (Fig. 4). This is consistent with the correlation we reported previously between the $N / D_{\text {index }}$ for $\mathrm{C} 5-\mathrm{C} 6 \mathrm{C}$. finmarchicus and the herring SSB for a more restricted time-series (1960 to 1990). When the herring total biomass was low, the $N / D_{\text {index }}$ for $\mathrm{C} 5-\mathrm{C} 6 \mathrm{C}$. finmarchicus was close to 1.0, suggesting that little DVM was occurring and, when the herring biomass was greater, the $N / D_{\text {Index }}$ was $>1.0$, suggesting that the NDVM behaviour of C5-C6 C. finmarchicus was stronger This observation is consistent with the hypothesis we proposed previously that inter-annual variability in the abundance of herring in the North Sea over recent decades has caused inter-annual variability in the NDVM behaviour of C5-C6 C. finmarchicus (Hays 1995a). One might criticise this hypothesis because the herring total biomass only accounted for $46 \%$ of the inter-annual variability in the $N / D_{\text {index }}$ for $\mathrm{C} 5-\mathrm{C} 6 \mathrm{C}$. 


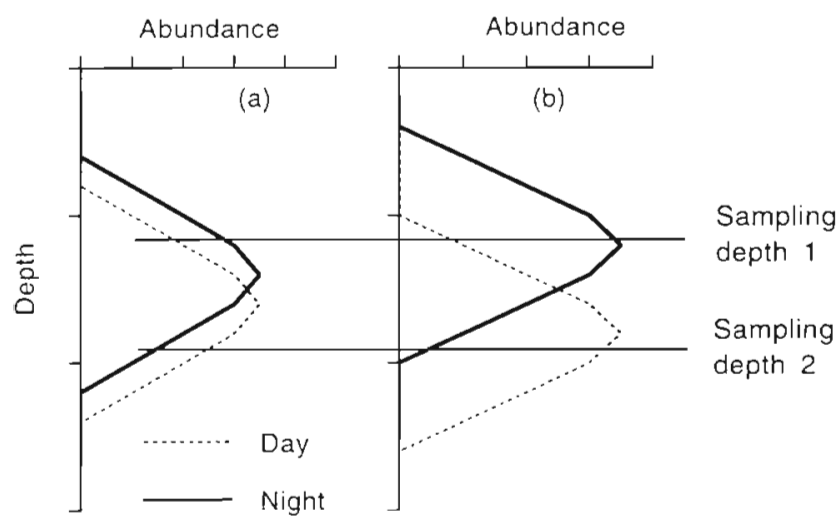

Fig. 10. Schematic representation of some of the difficulties in making a precise interpretation of changes in the $N / D_{\text {index }}$ for species that occur near the surface and only undergo NDVM with an amplitude of a few metres. The extent of NDVM has increased between (a) and (b) but, depending on the sampling depth, this change in NDVM behaviour could produce either an increase in the $N / D_{\text {index }}$ (sampling depth 1) or a decrease in the $N / D_{\text {index }}$ (sampling depth 2)

finmarchicus. However, our calculations suggest that the residual variation can be explained by the inaccuracy with which the $N / D_{\text {index }}$ was estimated.

If, as we suggest, there have been long-term changes in the intensity of visual predation in the North Sea in recent decades, then long-term changes in the DVM behaviour of other copepods in this region might be expected. For the same time period (1958 to 1994) we therefore calculated the $N / D_{\text {index }}$ for the 6 other most abundant copepod taxa in the CPR records from the North Sea and compared these values with the herring total biomass. The $N / D_{\text {Index }}$ for all 6 of these taxa showed long-term trends that co-varied with the herring total biomass (Fig. 7). Again the unexplained variation in these relationships could be accounted for by the inaccuracy with which the $N / D_{\text {index }}$ was estimated (Fig. 8). These findings suggest that long-term changes in DVM behaviour in the North Sea have not been restricted to $\mathrm{C} 5-\mathrm{C} 6$ Calanus finmarchicus, but have also occurred in many other abundant zooplankton taxa as well.

The sign of the correlation (+ or -) between the $N / D_{\text {index }}$ and the herring total biomass varied between taxa (Fig. 7). Thus for Temora longicornis, Para-PseudoCalanus, Centropages hamatus and Acartia clausii, the $N / D_{\text {index }}$ was higher when herring were scarce and lower when herring were abundant, which was the opposite pattern to that found for C5-C6 Calanus finmarchicus, Calanus spp. C1-C4 and Centropages typicus

In trying to explain these inter-taxa differences, we need to look closely at what the $N / D_{\text {index }}$ may be measuring for different species. The main problem with this measurement is that nothing is known of the diel changes in the depth of the sampled population, i.e. the fixed near-surface sampling depth of the CPR can give no information on the amplitude of NDVM (see Hays 1994 for further discussion). For certain copepods, such as members of the family Metridiidae (e.g. Metridia spp. and Pleuromamma spp.), the amplitude of NDVM is typically very large (several 10 s or 100 s of metres), with the populations only being near the surface at night (Longhurst \& Williams 1979). For such species the CPR, due to its near-surface sampling depth, will tend to catch much greater numbers at night compared to during the day and hence the $N / D_{\text {index }}$ will be directly related to the extent of NDVM (Hays et al. 1994). Similarly Calanus spp. may, on certain occasions, undergo NDVM with an amplitude of several 10 s of metres (e.g. Frost 1988) and so the $N / D_{\text {index }}$ is likely to be directly related to the extent of NDVM for this genus. However, for smaller copepods such as Temora longicornis, Pseudocalanus, Centropages hamatus and Acartia clausii, the amplitude of NDVM is generally only a few metres, with these species always being close to the surface (Longhurst \& Williams 1979, Harris 1988). For small species NDVM may consequently be evident either as a high $N / D_{\text {index }}$ value (when the population centre is mainly below the CPR sampling depth during the day and closer to the CPR sampling depth during the night) or as a low $N / D_{\text {index }}$ value (when the population centre is mainly close to the CPR sampling depth during the day and above the CPR sampling depth during the night). The precise interpretation of the $N / D_{\text {index }}$ for small copepods is therefore problematic, with the $N / D_{\text {index }}$ either getting larger or smaller as the extent of NDVM increases (Fig. 10). The difference in the signs of the correlations ( + or - ) between the $N / D_{\text {Index }}$ for the different copepods and the herring stock could, therefore, broadly reflect either size-dependent differences in the nature of the information given by the $N / D_{\text {index }}$ or size-dependent differences in the nature of their changes in NDVM behaviour. While a precise interpretation of differences in the $N / D_{\text {undex }}$ may be difficult to make for small species, a temporal change in the $N / D_{\text {index }}$ would, nevertheless, suggest that some systematic change in DVM behaviour had occurred. Our finding that between 1958 and 1994 the time-series of $N / D_{\text {index }}$ values for the most abundant copepod taxa in the North Sea were all well correlated with the size of the herring stock therefore suggests that systematic predator-induced decadal changes in zooplankton NDVM behaviour have been widespread in the North Sea ecosystem.

Acknowledgements. We thank John Nichols (MAFF, Lowestoft) for help concerning the fisheries data, Andy Yule for statistical advice, Mike Heath (SOAFD) and Doug Beare (Strathclyde) for useful discussions on this work and ICES for allowing us to use data from their working group reports. This 
paper forms part of PRIME (Plankton Reactivity In the Marine Environment), a programme funded by the Natural Environmental Research Council of the United Kingdom. This is PRIME contribution number 11

\section{LITERATURE CITED}

Anonymous (1990a) Report of the industrial fisheries working group. CM-ICES 1990/Assess:13

Anonymous (1990b) Report of the mackerel working group. CM-ICES 1990/Assess: 19

Anonymous (1994) Report of the industrial fisheries working group. CM-ICES 1994/Asses5:7

Anonymous (1995) Report of the herring assessment working group for the area south of $62^{\circ} \mathrm{N}$. CM-ICES 1995/Assess: 13

Bollens SM, Frost BW (1989) Zooplanktivorous fish and variable diel vertical migration in the marine planktonic copepod Calanus pacificus. Limnol Oceanogr 34:1072-1083

Brooks JL, Dodson SI (1965) Predation, body size, and composition of plankton. Science 150:28-35

Burd AC (1978) Long-term changes in the North Sea herring stocks. Rapp PV Réun Cons Int Explor Mer 172:137-153

Corten A (1990) Long-term trends in pelagic fish stocks of the North Sea and adjacent waters and their possible connection to hydrographic changes. Neth J Sea Res 25:227-235

Corten A, van de Kamp G (1992) Natural changes in pelagic fish stocks of the North Sea in the late 1980s. ICES Mar Sci Symp 195:402-417

Cushing DH (1980) The decline of the herring stocks and the gadoid outburst. J Cons Int Explor Mer 39:70-81

Frost BW (1988) Variability and possible adaptive significance of diel vertical migration in Calanus pacificus, a planktonic marine copepod. Bull Mar Sci 43:675-694

Gliwicz ZM (1986a) Predation and the evolution of vertical migration in zooplankton. Nature 320:746-748

Gliwicz ZM (1986b) A lunar cycle in zooplankton. Ecology 67 $883-897$

Hardy AC (1936) Plankton ecology and the hypothesis of animal exclusion. Proc Linn Soc Lond 148:64-70

Hardy AC, Gunther ER (1936) The plankton of the South Georgia whaling grounds and adjacent waters 1926-27. Discovery Rep 11

Harris MP, Bailey RS (1992) Mortality rates of puffin Fratercula arctica and guillemot Uria aalge and fish abundance in the North Sea. Biol Conserv 60:39-46

Harris RP (1988) Interactions between diel vertical migratory behavior of marine zooplankton and the subsurface chlorophyll maximum. Bull Mar Sci 43:663-674

Hays GC (1995a) Zooplankton avoidance activity. Nature $376: 650$

This article was submitted to the editor
Hays GC (1995b) Diel vertical migration behaviour of Calanus hyperboreus at temperate latitudes. Mar Ecol Prog Ser 127:301-304

Hays GC, Proctor CA, John AWG, Warner A.J (1994) Interspecific differences in the diel vertical migration of marine copepods: the implications of size, colour and morphology Limnol Oceanogr 39:1621-1629

Hays GC, Warner A.J (1993) Consistency of towing speed and sampling depth for the Continuous Plankton Recorder J Mar Biol Ass UK 73:967-970

Hays GC, Warner AJ, Proctor CA (1995) Spatio-temporal patterns in the diel vertical migration of the copepod Metridia lucens in the northeast Atlantic derived from the Continu. ous Plankton Recorder survey. Limnol Oceanogr 40 : $469-475$

Lampert W (1989) The adaptive significance of diel vertical migration of zooplankton. Funct Ecol 3:21-27

Last JM (1989) The food of the herring, Clupea harengus, in the North Sea, 1983-1986. J Fish Biol 34:489-501

Longhurst A, Williams $R$ (1979) Materials for modelling: vertical distribution of Atlantic zooplankton in summer J Plankton Res 1:1-28

Machacek J (1993) Comparison of the response of Daphnia galeata and Daphnia obtusa to fish-produced chemical substance. Limnol Oceanogr 38:1544-1550

Monaghan P (1992) Seabirds and sandeels: the conflict between exploitation and conservation in the northern North Sea. Biodivers Conserv 1:98-111

Neill WE (1990) Induced vertical migration in copepods as a defence against invertebrate predation. Nature 345 $524-526$

Neill WE (1992) Population variation in the ontogeny of predator-induced vertical migration of copepods. Nature 356:54-57

Oceanographic Laboratory Edinburgh (1973) Continuous Plankton Records: a plankton atlas of the North Atlantic and North Sea. Bull Mar Ecol 7:1-174

Ohman MD, Frost BW, Cohen EB (1983) Reverse diel vertical migration - an escape from invertebrate predators. Science 220:1404-1407

Pearre S Jr (1979) On the adaptive significance of vertical migration. Limnol Oceanogr 24:781-782

Russell FS (1934) The vertical distribution of marine macroplankton XII. Some observations on the vertical distribution of Calanus finmarchicus in relation to light intensity. J Mar Biol Ass UK 19:569-584

Verity PG, Smetacek V (1996) Organism life cycles, predation, and the structure of marine pelagic ecosystems. Mar Ecol Prog Ser 130:277-293

Warner AJ, Hays GC (1994) Sampling by the Continuous Plankton Recorder survey. Prog Oceanogr 34:237-256

Manuscript first recelved: April 25, 1996

Revised version accepted: June 10, 1996 